\title{
La presencia de G.W.F. Hegel en representantes de la filosofía latinoamericana (L. Zea, A. Roig, E. Dussel, I. Ellacuría)
}

\author{
The presence of G.W.F. Hegel in representatives of the \\ Latin American philosophy \\ (L. Zea, A. Roig, E. Dussel, I. Ellacuría) \\ MICHAEL SCHULZ \\ Rheinische Friedrich-Wilhelms Universität (Alemania)
}

Recibido:21-03-2014 Aceptado definitivamente:22-04-2014

\begin{abstract}
RESUMEN
No obstante de sus críticas de la potencialidad filosófica de América, intuiciones y argumentos de Hegel están presentes en los planteamientos de representantes importantes de la Filosofía latinoamericana, aunque siempre de una manera crítica. Conceptos claves del pensamiento de Zea, Roig, Dussel y Ellacuría - como «proyecto asuntivo», «sujeto empírico», «analéctica»y «respectividad» - indican al mismo tiempo el foco de sus discusiones con Hegel. Tal análisis permite la conclusión sorprendente de que Hegel ofrece elementos esenciales para el esbozo de una filosofía intercultural.

\section{PALABRAS CLAVES}

HEGEL EN LA FILOSOFÍA LATINOAMERICANA, PROYECTO ASUNTIVO, ANALÉCTICA, RESPECTIVIDAD, FILOSOFÍA INTERCULTURAL
\end{abstract}

\footnotetext{
ABSTRACT

Despite Hegel's critique of American's philosophical potentiality, Hegel's intuitions and arguments are present in approaches of important representatives of Latin American philosophy, although always in a critical manner. Zea's, Roig's, Dussel's and Ellacuría's key concepts - such as the «assumptive project», «empirical subject», «a-

Suplemento 19 (2014)

(C) Contrastes. Revista internacional de filosofia, pp. 285-309. ISSN: 1136-9922 Departamento de filosofía, Facultad de Filosofía y Letras, Universidad de Málaga Campus de Teatinos, E-29071 Málaga (España)
} 
nalectic» and «respectivity»-indicate at the same time the focus of their discussion with Hegel. The analysis of the discussion with Hegel permits the surprising conclusion that Hegel offers essential elements for an outline of an intercultural philosophy.

\section{KEY WORDS}

HEGEL IN LATIN AMERICAN PHILOSOPHY, ASSUMPTIVE PROJECT, ANALECTIC, RESPECTIVITY, INTERCULTURAL PHILOSOPHY

El COMIENZO DE UNA FILOSOFía LATINOAMERICANA ${ }^{1}$ se debe al siglo XIX. Después de la emancipación política se busca una liberación intelectual. En 1842 es Juan Bautista Alberdi (1810-1884) que en Montevideo proclama la necesidad de una filosofía propia del continente. ${ }^{2}$ La necesidad de esta filosofía no puede sino ser consecuente con las necesidades propias en que los países latinoamericanos se encuentran; siendo ellas mismas las que marcan el perfil y temas de la filosofia. El primer tema que Alberdi reclama es el de la liberación, y de este modo queda inaugurada la gran indicación temática que determina el desarrollo de la filosofía latinoamericana que durante el siglo XX acontece. La filosofía adquiere así un perfil práctico y político, orientándose hacia un futuro en el que debiera darse cumplimiento la libertad en una sociedad siempre más justa y equilibrada.

Una filosofía que se alienta preferentemente a la cuestión de la liberación, está igualmente vinculada con el asunto universal de la libertad humana y de la historia. La historia es la realidad que la libertad humana constituye. Para la filosofía latinoamericana es típico que temas universales reciben un perfil regional. Como vamos a ver, la regionalidad funciona como criterio para la autenticidad de principios universales.

Protagonistas de una filosofía latinoamericana entienden la filosofía de Georg Wilhelm Friedrich Hegel (1770-1831) como un instrumento para conceptualizar sus intenciones originarias. ${ }^{4} \mathrm{Su}$ dicho conocido «la historia mundial es el

1 Cfr., Beorlegui 2006.

2 Cfr., Alberdi 2003, p. 16: «La filosofía, pues, una en sus elementos fundamentales como la humanidad, es varia en sus aplicaciones nacionales y temporales. [...] no hay más que una filosofía. La filosofía se localiza por sus aplicaciones especiales a las necesidades propias de cada país y de cada momento.».

3 Cfr., Alberdi 2003, p. 18: «Así, pues, libertad, igualdad, asociación, he aquí los grandes fundamentos de nuestra filosofía moral.»

4 Cfr., Zea 1976, p. 530: «Las filosofías de Hegel y Marx, hemos dicho, han venido a ser las filosofías en que mejor apoyo ha encontrado la filosofía latinoamericana contemporánea en sus esfuerzos por tomar conciencia de su realidad, y trascender las yuxtaposiciones que ésta le presenta.» Cfr. Sauerwald 1985; Schutte 1990; Santos Herceg 2010. 
progreso de la conciencia de la libertad» $\rangle^{5}$ se entiende como esperanza en el progreso del continente. Sin compartir el idealismo absoluto de Hegel, se define la historia como el objeto de la filosofía y se concibe una filosofia de la historia. Este planteamiento une pensadores varios aunque se distinguen en su orientación metafísica. El artículo presenta sólo unos representantes que se orientan a Hegel aunque siempre de una manera crítica: el mexicano Leopoldo Zea, el argentino Arturo Roig, el argentino de origen Enrique Dussel y el españolsalvadoreño Ignacio Ellacuría. Zea y Roig son los dos filósofos que asumen en particular ideas de Hegel, por eso el tratamiento de su pensamiento encuentra más atención. Termino con unas consideraciones a manera de esbozo sobre la filosofía intercultural y la filosofía de la religión.

\section{L. ZEA: EL PROYECTO ASUNTIVO}

Leopoldo Zea (1912-2004) ${ }^{6}$ aprovecha la filosofía de Hegel en su manera de concebir su filosofía de la historia, y su proyecto asuntivo ${ }^{7}$ y de liberación. A través de su maestro, José Gaos (1900-1969), ${ }^{8}$ aprende a estudiar la historia del pensamiento como camino para tomar conciencia de la propia identidad. $\mathrm{Y}$ es también Hegel que interpreta la historia como revelación y constitución de la conciencia del hombre de sí mismo. Este tomar conciencia encuentra su cumplimiento en el momento en que el hombre se descubre como manifestación de un absoluto que se revela y realiza en la historia por naturaleza y espíritu ${ }^{9}$. Aunque Zea no simpatiza con el concepto de un absoluto divino haciéndose espíritu a través de la historia, comparte la dimensión antropológica de la concepción de historia en Hegel. ${ }^{10}$ En particular, Zea entiende el estudio de la historia espiritual y política del continente como tomar conciencia de la identidad latinoamericana y de la mexicana ${ }^{11}$. En la historia de Latinoamérica se encuentra el crecimiento de la conciencia en sus distintas configuraciones.

Primero, explica Zea, ${ }^{12}$ la historia latinoamericana se muestra determinada por una perspectiva alienada. Por su nacimiento colonial, Latinoamérica es un proyecto europeo con motivos varios y contradictorios: prolongación de Europa (EEUU) y la negación de la vieja Europa, periferia del centro europeo y conti-

5 Hegel, Vorlesungen über die Philosophie der Geschichte, p. 32: «Die Weltgeschichte ist der Fortschritt im Bewusstsein der Freiheit - ein Fortschritt, den wir in seiner Notwendigkeit zu erkennen haben.»

6 Cfr., Beorlegui 2006, pp. 586-605; Hofstätter 2006; Estermann 2008.

7 Cfr., Zea 1978 pp. 269-294.

8 Cfr., Beorlegui 2006, pp. 515-528: De origen español, exilado - o transterrado como él mismo decía - por la guerra civil, en 1941 obtuvo la ciudadanía mexicana.

9 Cfr., Hegel, Vorlesungen über die Philosophie der Geschichte, pp. 77, 86, 104-105.

10 Cfr., Zea 1978, pp. 47-55.

11 Cfr., Zea 1978, pp. 15-43.

12 Cfr., Zea 1978, pp. 16-19, 26-35, 165-187.

Suplemento 19 (2014) de Contrastes. Revista internacional de filosofía 
nente de esperanza y de innovación para Europa. Un complejo de inferioridad y una alienación caracterizan la conciencia latinoamericana que se define por la idea de deber ser algo y alguien distinto que es. ${ }^{13}$ Para superar esta alienación, Zea propone la Aufhebung de Hegel: la asunción de la propia historia en su complejidad y contradicciones para tomar consciencia de la propia identidad. Zea presenta varios proyectos culturales ${ }^{14}$ que crecieron en Latinoamérica y sintetizan distintos elementos europeos y las nuevas experiencias del continente.

(1) El proyecto libertario o bolivariano ${ }^{15}$ consiste en la unidad de los países latinoamericanos por los esfuerzos y batallas comunes por la independencia entre 1811 y 1824. Zea cita de la Carta de Jamaica (1815) de Simón Bolívar (1783-1830) en que pronuncia el nacimiento de «una gran Nación» - grande «por su libertad y gloria», no por extensión. ${ }^{16} \mathrm{La}$ «grandeza de los pueblos», explica Bolívar, se basa en su «largo sufrimiento»; esta grandeza comprende el instrumento de la nueva unión de los pueblos. ${ }^{17}$ Por otro lado, Zea aclara con referencia a Bolívar, el colonialismo quedaba presente en la mentalidad de los pueblos e impidió la realización de un subcontinente unido: «sobre la servidumbre era difícil, sino imposible, alzar la libertad». ${ }^{18}$ Zea identifica la ideología de la raza pura contra el mestizaje impuro como el instrumento fatal que posibilitó la dominación de una clase por la otra. Zea concluye: La victoria de la libertad política no encontró su correspondencia ni en la sociedad ni entre las sociedades y países latinoamericanos. Por eso, la historia de la libertad humana en Latinoamérica necesita un desarrollo ulterior. Hasta ahora la lucha no ocurrió entre el poder colonial y Latinoamérica «sino entre España y España. Una España más joven, pero España al fin, es la que ha vencido a la vieja España. Nada ha cambiado...». ${ }^{19}$

(2) El pensamiento de Andrés Bello (1781-1865) ofrece el paradigma del segundo proyecto, que Zea cualifica como el proyecto conservador. ${ }^{20}$ Se trata del plan de aceptar liberalmente las estructuras heredadas del tiempo de la colonia. Pero Zea y otros autores reconocen en este concepto el motivo de muchos conflictos nuevos y la separación del continente. La libre aceptación de las estructuras coloniales no es motivo suficiente de su purificación y conversión en la realización efectiva de la libertad mental.

13 Cfr., Zea 1974, p. 17.

14 Cfr., Zea 1978, pp. 188-294; resumen en Beorlegui 2006, pp. 602-605; Hofstätter 2006, pp. 161-172; Estermann 2008, pp. 93-100.

15 Cfr., Zea 1978, pp. 188-210.

16 Zea 1978, p. 189.

17 Zea 1978, p. 192.

18 Zea 1978, p. 204.

19 Zea 1976, p. 58.

20 Cfr., Zea 1978, pp. 211-243. 
(3) El tercer proyecto, el de la civilización, se orienta a la libertad realizada en el liberalismo ilustrado de los Estados Unidos. ${ }^{21}$ Este modelo encontró una gran aceptación. Domingo Faustino Sarmiento Albarracín (1811-1888), presidente de Argentina (1868-1874) promovió este proyecto de la civilización contra la barbarie del país, representada por el mestizaje, el caudillismo y la cultura indígena. ${ }^{22}$ Se esperaba un progreso civil, científico y técnico de un «blanqueamiento» de los países por nuevos inmigrantes del norte de Europa. Zea crítica este proyecto por su intento de establecer una oligarquía, de una «pseudoburguesía ${ }^{23}$ occidental que quita la libertad a la mayoría de la población. Además intensifica la alienación de Latinoamérica de sus raíces históricas. Es un proyecto contra la propia historia. De Hegel Zea recibe la idea de la negación como motor de la historia de libertad. Pero esta negación pierde su dinámica dialéctica en el caso que se la comprenda como negación simple. El proyecto civilizador procede según el modelo de una negación simple, negando la propia historia y poniendo un presente y futuro alíenos. ${ }^{24}$

(4) En el proyecto asuntivo ${ }^{25}$ que propone Zea, la negación sirve a la Aufhebung, es decir, la negación niega posiciones en sus formas extremas por reconciliarlas con posiciones opuestas. ${ }^{26}$ Ya formalmente Zea distingue su enfoque no negando planteamientos opuestos. La negación niega la unilateralidad de los proyectos conservador y civilizador, sin negar elementos e intuiciones de estos proyectos que pertenecen a la historia latinoamericana. Esta historia ofrece además enfoques que preparan el proyecto asuntivo. Zea se refiere al representante del primer proyecto, a Simón Bolívar, y añade al escritor y mártir por la independencia de Cuba, José Martí (1853-1895). Sobretodo el ensayo políticofilosófico Nuestra América (1891) designa, según Zea, el proyecto asuntivo. Como Bolívar que rechaza simples imitaciones de Europa en cuestiones de constitución, de forma de gobierno y de la política y opta por innovaciones creativas, asimismo Martí aporta la idea de lo creativo a pesar de su carácter improvisado e imperfecto; pero es algo propio. Martí aboga formas experimentales en todas las áreas de la cultura y política que sintetizan elementos tradicionales con las experiencias nuevas del nuevo mundo. En filosofía, la sabiduría indígena tendría que ocupar el pensamiento griego. El sujeto de la filosofía es el hombre

21 Cfr., Zea 1978, pp. 244-268.

22 Cfr., su libro programático Facundo. Civilización y barbarie en las Pampas Argentinas (1845).

23 Zea 1978, p. 267; Zea 1976, pp. 103-105, 143-150: “Sajonización de Hispanoamérica (p. 146).

24 Cfr., Zea 1976, pp. 20-21.

25 Cfr., Zea 1978, pp. 269-294.

26 Hegel habla de una negación determinada (bestimmte Negation), es decir que se refiere a un aspecto de lo negado, a un aspecto indeterminado, inmediato, unilateral. Cfr. Hegel, Phänomenologie, p. 74 
natural, que es el mestizo quien naturalmente une y sintetiza los distintos orígenes de la población y no deja espacio a un racismo nuevo, postcolonial. ${ }^{27}$ Zea juzga el pensamiento de Martí como ya un punto culminante del proyecto asuntivo. ${ }^{28}$ Pero enumera a otros que orientaban su pensamiento hacia la misma dirección: como José Enrique Rodó (1871-1917) que rechaza el proyecto civilizador a favor de una espiritualidad propia de Latinoamérica, o José Vasconcelos (1882-1959) cuya idea de la raza cósmica afirma la noción del mestizaje como concepto cultural y sintetizador. ${ }^{29}$ Igualmente afirma la fuerza intelectual sintética de José Carlos Mariátegui (1894-1930) que busca una inculturación del marxismo en la cultura peruana basándose también en ideas incas de la propiedad común. La idea de la liberación del poder colonial y de la alienación, Zea la reconoce además en la obra de Bartolomé de Las Casas $(1484 / 1485-1566)^{30}$. Las Casas sabía aplicar el pensamiento europeo a las experiencias nuevas de América para justificar los derechos de la población de origen. Este fraile, como otros, pertenece a la historia de la liberación latinoamericana y al progreso en libertad. Ellos aportaron desde el comienzo de la historia colonial elementos esenciales del proyecto asuntivo. Zea lista muchos nombres de pensadores que le parecen contribuir con elementos contundentes al proyecto asuntivo. De tal modo se opone contra las invectivas del peruano Augusto Salazar Bondy (1925-1974) contra la existencia verdadera de una filosofia latinoamericana: la dependencia multíplice de Latinoamérica de Europea y de los Estados Unidos impediría el desarrollo de una filosofía autentica y originaria. ${ }^{31}$ La respuesta de Zea es el concepto asuntivo que ni condena las tradiciones humanistas de Europa, ni niega la historia propia que conoce la opresión y la rebelión contra esa en acciones y formas de pensamiento. También el marxismo y socialismo preferidos por muchas partes, juzga Zea, puede favorecer una nueva forma de colonización por el pensamiento europeo. La filosofía de la liberación de Zea intenta superar tales unilateralidades; quiere abrirlas a otras perspectivas que resultan de la historia latinoamericana.

La filosofía de la historia de Zea muestra la necesidad del desarrollo intelectual, social y político. Se presenta el proyecto asuntivo como el fin de la historia, como la base de una liberación que requiere más su realización. La necesidad del desarrollo no resulta de la lógica de un sistema; en este punto Zea no sigue a Hegel. Son las unilateralidades, tensiones y contradicciones en los varios proyectos que empujan el proceso dialéctico hacia una conciencia latinoamericana de sí misma que es la condición de la liberación y de su realización social.

27 Cfr., Martí 2005, pp. 31-39.

28 Cfr., Zea 1978, pp. 42-43.

29 Cfr., Zea 1978, p. 274.

30 Cfr., Estermann 2008, p. 99.

31 Cfr., Salazar Bondy 2006, p. 68, 125; sobre el debate Zea-Salazar Bondy cfr. Beorlegui 2006, pp. 597-602. 
Como he mencionado, Zea asume de Hegel la «herramienta» de la negación determinada y la aplica a la negación de esta unilateralidad de los proyectos, conservando elementos centrales para integrarlos en el nivel próximo y más alto y avanzado. Zea no quiere jamás negar el humanismo europeo, sino su pertenencia intrínseca y exclusiva al proyecto conservador. Integra el humanismo en la idea del mestizaje donde el humanismo encuentra su concretización latinoamericana. Por otro lado, Zea presenta este humanismo del mestizaje como modelo universal: como modelo de la integración de distintas culturas mundiales. ${ }^{32} \mathrm{De}$ lo concreto se abre hacia lo universal. Zea traduce esta combinación de los concreto y de lo universal en una verdad antropológica. El hombre mismo es la unidad de lo concreto y universal. A un nivel metafísico Zea sostiene que el ser humano es siempre y sólo un ser concreto, único y distinto de todos; somos todos desiguales. Pero en esta desigualdad consiste la igualdad, lo universal del hombre. ${ }^{33}$ Esta dialéctica antropológica que aplica la dialéctica de Hegel entre unidad y diferencia, encuentra su traducción en el nivel cultural: Zea está convencido de que por el ser humano común un entendimiento intercultural es posible. ${ }^{34}$ Por eso se puede siempre identificar ideas comunes en la diferencia cultural de sus expresiones. En esta perspectiva la historia de la humanidad forma siempre una unidad integral.

Una problemática de la filosofía de Hegel se continúa también en el enfoque de Zea. Por la concentración en la síntesis e integración que determina el desarrollo histórico y el progreso de libertad, Zea pierde una comprensión para los pueblos indígenas que no se quieren integrar en el concepto del mestizaje, que prefieren conservar su inmediatez como población de origen. ${ }^{35}$ Él reduce el conflicto de Chiapas en México que se levantó 1994, a un conflicto socialeconómico, a una falta de integración de la población indígena. No obstante, debe decirse que los rebeldes no se levantaron por un asunto sólo socialeconómico; según sus propias palabras los problemas económicos se basaban en la discriminación racial. Pensadores posmodernos reconocen la dificultad clásica en la filosofía de la historia que Zea, inspirado por Hegel, designa como una uniforme meta-narración - la del mestizaje - que no deja espacio a las narraciones particulares - para pueblos que rechazan ser integrados en una realidad que les trasciende y les relativiza y que estiman su libertad. ${ }^{36}$ La filosofía de la liberación, fundada en una meta-narración, causa así su contrario: una falta de libertad.

32 Cfr., Zea 1976, pp. 324-325, 428-430; Zea 1978, pp. 274, 290.

33 Cfr., Zea 1990, p. 107.

34 Cfr., Hofstätter 2005, pp. 185-189.

35 Cfr., Hofstätter 2006, pp. 194-203; Estermann 2008, pp. 105-115.

36 Cfr., Castro-Gómez 1996, pp. 104-120. 
Por otro lado, a la propuesta de Zea dentro de la problemática del diálogo intercultural, no se le puede contestar con una simple negación, dado que su concepto antropológico debilita la tesis de una incompatibilidad de las culturas. La observación y el argumento de que la historia de las culturas revela nociones y proyectos comunes como la libertad del hombre o el deseo humano de liberación, es importante en un mundo globalizado. El proyecto asuntivo no cae en la trampa de sólo copiar el eurocentrismo invertido lateralmente poniendo ahora Latinoamérica el centro del mundo. Zea busca el centro de la identidad latinoamericana asumiendo la propia historia y tomando conciencia de la propia genealogía. No se trata de una identidad negativa, que Hegel entiende como una identidad que se define por la negación de su contrario (europea) imitando su contrario.

Zea interpreta la conocida dialéctica entre amo y esclavo (señor y siervo, Herr und Knecht) en términos culturales. Europa, el amo, toma conciencia de sí mismo y de sus conquistas y expansiones colonialistas. ${ }^{37}$ Por eso Latinoamérica constituye el otro lado de la identidad europea - lo que, al comienzo de la conquista, no estaba evidente. Pero por la resistencia del territorio conquistado al nivel intelectual y legislativo, por los movimientos de rebelión y revolución, por independencia política, Europa toma siempre más conciencia de su identidad verdadera y concreta - igualmente Latinoamérica descubrió su conciencia de libertad, capacidad de escribir su historia a partir de la conquista hasta la independencia. Zea argumenta que la dialéctica no termina en la imitación del amo por el esclavo, sino en un reconocimiento recíproco. Este reconocimiento ayuda a ampliar la racionalidad europea, que, según Zea, está abierta sólo a una visión de la realidad. El reconocimiento del esclavo anterior - del otro - como alteridad no-extinguible abre la racionalidad europea al diálogo e intercambio cultural. Esto es la liberación de Europa. Igualmente la identidad latinoamericana desarrolla la capacidad dialogal. No se niega la herencia europea, tampoco se imita la unilateralidad de la racionalidad europea. En lugar de eso, se integra esta herencia en la identidad histórica y sintética. Esto es la liberación de Latinoamérica. Las dos liberaciones abren una horizonte de una racionalidad dialogal e intercultural. Esta interpretación de Hegel es posible porque Zea no se refiere al concepto hegeliano de la subjetividad y el espíritu absoluto, sino se limita al espíritu del hombre. Generalmente el concepto hegeliano del absoluto provoca la crítica de que la filosofía de Hegel no salva la alteridad, sino que la reduce a un momento en el proceso de la auto-realización del espíritu absoluto el cual es determinado por la estructura de una subjetividad omni- abarcante. ${ }^{38}$ Dado que según Hegel el espíritu del hombre es la presencia del espíritu absoluto, también el espíritu humano europeo revela esta ambigüedad precaria y peligrosidad para

37 Cfr., Zea 1976, p. 183; Schutte 1990, pp. 9-12.

38 Cfr., Schutte 1990, p. 10, hace esta observación. 
la alteridad: Hegel dice que sólo por el acercarse del espíritu, las culturas «naturales» de México y Perú se perdieron. ${ }^{39}$

Con su concepto de la racionalidad dialogal, Zea muestra más abertura a la alteridad que en su crítica de aquellos pueblos indígenas que no siguen el camino de la integración. Ya Martí que Zea identifica como el comienzo de la filosofia latinoamericana, subraya la importancia de la sabiduría indígena para entender la naturaleza de Latinoamérica. Respecto a esta problemática se puede utilizar a Zea contra Zea.

En fin, Zea crítica la aserción negativa de Hegel sobre América - que es «el eco y reflejo del Viejo Mundo», y que queda sin propio pensamiento por falta de historia y es sólo la «Tierra del futuro». ${ }^{40}$ Por otra parte Zea toma la cualificación de América como tierra del futuro en el sentido de una promesa. Se trata de un futuro que ya comenzó con la historia de la liberación en Las Casas y Francisco de Vitoria y que erróneamente Hegel no reconoce. Este futuro es - desde la perspectiva de Hegel - el siglo XIX con sus comienzos de la filosofía latinoamericana en Bolívar, Alberdi y Martí, y continúa hasta que el proyecto asuntivo se convierte más completamente en realidad social y política.

\section{ARTURO ROIG: SUJETO EMPÍRICO}

El filósofo argentino Arturo Roig (1922-2012) ${ }^{41}$ critica que Zea acepta parcialmente la opinión de Hegel sobre América porque de tal modo oculta las filosofías implícitas de las tradiciones precolombinas y populares. Es interesante notar que Roig llega a esta crítica por una revisión de los criterios que Hegel pone al definir el comienzo de la filosofía. Hegel lista dos criterios que Roig, en primer lugar, acepta: ${ }^{42}$ (1) la capacidad del hombre de pensar lo absoluto y universal en términos conceptuales, independiente de representaciones mitológicas, religiosas o artísticas, es el pensamiento puro en forma de la lógica y (2) la condición social-política de que una sociedad descubre la libertad como atributo de sus miembros que realizan un para sí. Bajo estas condiciones empieza, afirma Roig en sintonía con Hegel, el pensamiento filosófico como un ponerse para $s i{ }^{43}$ La pasión de Roig por la filosofía griega, le dejó aceptar esta criteriología

39 Cfr., Hegel, Vorlesungen über die Philosophie der Geschichte, p. 108.

40 Hegel, Vorlesungen über die Philosophie der Geschichte, p. 114: «Amerika ist das Land der Zukunft... Was bis jetzt sich hier ereignet, ist nur der Widerhall der Alten Welt...»

41 Cfr., Mahr 2000; Beorlegui 2006, pp. 644-653; Sauerwald 1985, pp. 237-245; Schutte 1990; Santos Herceg 2010, pp. 51-53, 55-58.

42 Cfr., Hegel, Vorlesungen über die Geschichte der Philosophie I, pp. 115-117; Roig 1981, INTRODUCCIÓN.

43 Cfr., Hegel, Vorlesungen über die Geschichte der Philosophie I, p 116: Libertad existe donde «das Subjekt das Bewusstsein der Persönlichkeit erlangt hat, also schlechthin für sich gelten will.» Roig 1981, cap. IV. «Se trata de un sujeto que como hemos dicho, repitiendo a 
de Hegel; pero su estudio del pensamiento latinoamericano condujo a Roig a la convicción que no existe un comienzo solo, sino de que son varios principios en los cuales ocurre el «ponerse para sí como valioso», la constitución de sujeto que se descubre «en su tarea de autoconocimiento». ${ }^{44}$ Por la importancia de los demás para la constitución del sujeto, Roig reformula el acto que funda el comienzo de la filosofía proponiéndolo como el «ponernos a nosotros mismos como valiosos». ${ }^{45}$

Este comienzo se encuentra implícitamente en la sabiduría indígena ${ }^{46}$ explícitamente en Alberdi y Martí. El comenzar del hombre, su «ponerse para sí» revela un a priori antropológico, ${ }^{47}$ que Roig sostiene, determina la historia. ${ }^{48} \mathrm{El}$ filósofo argentino observa también retornos que abandonan el «ponerse para sí como valioso», p. e., el movimiento de un neocolonialismo que niega el valor propio del pensamiento latinoamericano. Por eso la filosofía tiene que empezar varias veces, es su tarea permanente evitar retornos a estadios superados. ${ }^{49}$ Tampoco en Europa, la lógica de Aristóteles impedía retornos a «pensamientos impuros»; de tal modo, también la filosofía europea conoce más comienzos que uno solo.

Igualmente como Zea, Roig rechaza el concepto del absoluto: en el desarrollo del espíritu humano se manifiesta sólo el espíritu del hombre. Por este motivo el pensamiento de Roig no se orienta a verdades lógicas y eternas, sino más a la realidad concreta en sus cambios. También el sujeto de la filosofía tiene que ser entendido como un "sujeto empírico», requiere Roig contra Hegel (y Husserl).$^{50}$ Es el hombre con sus deseos y esperanzas quien desde su situación concreta designa la filosofía para una situación concreta. El «empirismo» del sujeto no lo reduce a un conjunto de datos físicos y biológicos. Roig usa este concepto para subrayar la existencia situativa e histórica de cada persona humana. Según la interpretación de Roig, Hegel desatiende esta dimensión de lo contingente, histórico y concreto privilegiando, también en el caso del hombre, un concepto que se concentra en la esencia abstracta del ser humano; cayendo, además en la ontología que termina por absorber lo histórico. ${ }^{51}$

Hegel, «se pone a sí mismo como valioso»y «considera como valioso el pensar sobre sí mismo».»

44 Roig 1971, pp. 2, 4. Cfr., Mahr 2000, pp. 46-51.

45 Roig 1971, p. 4.

46 Cfr., Roig 1974, pp. 220-221.

47 Cfr., Roig 1981, Introducción: «podemos enunciar el a priori antropológico que plantea Hegel, como un «querernos a nosotros mismos como valiosos».»

48 Cf., Roig 1981, Introducción.

49 Cfr., Roig 1971, p. 2.

50 Roig 1981, Introducción: «El a priori antropológico es el acto de un sujeto empírico para el cual su temporalidad no se funda, ni en el movimiento del concepto, ni en el desplazamiento lógico de una esencia a otra.» Cfr., Mahr 2000, pp. 99-102.

51 Cfr., Roig 1981, Introducción. 
Tomando en serio el aspecto histórico de la reflexión histórica, según Roig, la filosofía perdería su carácter vespertino a favor de un carácter matutino y profético. $^{52}$ Roig discute la idea de Hegel de que la filosofía puede sólo reflexionar sobre el pasado y la historia - por eso no hay filosofía en América según Hegel, por falta una larga historia. «La filosofia llega siempre demasiado tarde.» ${ }^{53}$ Sólo desde el fin de un proceso histórico en que una figura cultural o política nacieron, la filosofía alcanza a captar esta figura crecida y la puede pensar, analizar, evaluar y poner en relación con otras figuras del pasado y medir el progreso entre una figura o constelación anterior y de una de lo presente. Por eso la razón no puede transcender su tiempo, ni siquiera la filosofía, cuya tarea es según Hegel, entender lo que es y pasó. Jamás la filosofía es capaz de pronosticar; designando el futuro la razón se convierte en opinión subjetiva y se pone más allá de la verdad. La filosofía «es su tiempo aprehendido en pensamientos». ${ }^{54}$ Pero esta concepción hegeliana impide, sigue Roig, que la filosofía asuma el papel de un motor en el progreso humano, impotente de idear y planear el futuro. Roig insiste en esta función profética e innovadora de la filosofía; como filosofía matutina, a ella le compete la misión de diseñar figuras y constelaciones de la vida humana siempre más humana. Simón Bolívar le parece representar este pensamiento hacia el futuro - a diferencia de Hegel. ${ }^{55}$ El criterio conceptual que la filosofía puede fungir como fuerza del cambio social es su capacidad de concebir la alteridad.

Roig presenta la dialéctica entre amo y esclavo ${ }^{56}$ como un ejemplo en que Hegel abandona la posición privilegiada del espíritu único y absoluto, de la ontología y de la subjetividad abstracta. En cambio reflexiona la situación concreta y asimétrica de las dos auto-conciencias. Las dos no podrían existir para sí mismas, sólo son para sí mismas en reciprocidad estricta. Roig frena la Fenomenología del Espíritu aquí, no comparte la absorción de las dos auto-conciencias en un espíritu omni-abarcador. Él transciende la dialéctica de las dos hacia un «nosotros» porque a la situación empírica e histórica del hombre no pertenecen sólo dos personas, sino una comunidad y sociedad. El hombre es un ser político dice

52 Cfr., Roig 194, pp. 220, 230; Santos Herceg 2010, pp. 49-52.

53 Hegel, Grundlinien der Philosophie des Rechts, p. 28.

54 Ibid., p. 26: «Das was ist zu begreifen, ist die Aufgabe der Philosophie, denn das, was ist, ist die Vernunft. Was das Individuum betrifft, so ist es ohnehin jedes ein Sohn seiner Zeit; so ist auch de Philosophie ihre Zeit in Gedanken erfasst.»

55 Cfr., Roig 1981, cap. 7: «La filosofía de la historia que se desprende de los textos bolivarianos, se organiza sobre una fórmula radicalmente distinta de la expresada en el texto hegeliano: en el pensamiento del Libertador no hay que ocuparse «de lo que ha sido y de lo que es», sino de «lo que es y de lo que será», enunciado en el plano concreto de la contingencia de lo histórico.» Cf. Roig, 1986, p. 170.

56 Cfr., Roig 1981, p. 83; Schutte 1990, pp. 15-17. 
Roig con referencia a Aristóteles. ${ }^{57}$ Roig añade a esta definición aristotélica del ser humano la idea de que esta intersubjetividad es algo socialmente concreto, determinado por asimetrías y rupturas.

La ruptura del sujeto omni-abarcador, según Hegel, es el hombre explotado, marginado, oprimido. ${ }^{58}$ Esta alteridad concretamente determinada por su estado social impide que el sujeto regrese tranquilamente a sí mismo desde su mundo y objeto. En cambio, el sujeto queda abierto, incompleto, desafiado. Esto es el sujeto de la filosofía de la liberación. Se trata igualmente de la liberación del sujeto hipertrófico que determinaba el pensamiento, la acción y la política europeos. Este sujeto casi-absoluto se deshace en la posmodernidad; contra la muerte posmoderna del sujeto, Roig pone su idea social del sujeto y de la alteridad, de una objetividad que precede al sujeto. ${ }^{59}$ Este retratamiento del sujeto supera la coincidencia del ego cogito de René Descartes (1596-1650) con el ego conqueror de Hernán Cortés (1485-1547). ${ }^{60}$

El objeto del sujeto filosófico es, entonces, su mundo con los demás, es el mundo concreto de Latinoamérica. ${ }^{61}$ El ponerse a sí valioso con que empieza la filosofía, requiere una afirmación de la historia de este mundo por un futuro distinto. Esta reflexión conduce a una crítica de Hegel, de su concepción de la historia como progreso irresistible en la libertad. Según Roig, las rupturas en la historia de Latinoamérica, las destrucciones y desastres, los retornos intelectuales y culturales que hacen necesario muchos comienzos y re-comienzos sociales, políticos y re-comienzos de la filosofía latinoamericana - esta historia interrumpida y nuevamente continuada, no permitiría hablar de una evolución continua de la libertad en la historia. ${ }^{62}$ Roig se distancia igualmente de Zea que ve más el progreso continuo en la libertad. Este progreso recorre, según Zea, una dialéctica de tal modo de que rupturas, desviaciones y retornos no están excluidos. Por otra parte, Roig no comparte la idea posmoderna sobre el fin de las meta-narraciones. El filósofo argentino pone como ejemplo la pobreza y el hambre que son problemas globales; por ello es imposible renunciar a narraciones globales que afrontan la cuestión. ${ }^{63}$ Roig sospecha que la filosofía posmoderna no corresponde a un fuerte liberalismo económico que se opone a globales reglas sociales. La narración grande no se debe a un concepto a priori, sino es resultado de un discurso complejo y difícil - un discurso que queda abierto. En contraste, el concepto hegeliano describiría un discurso cerrado. Una apertura del concepto y discurso es indispensable, según Roig, para que la filosofía pueda corresponder

57 Cfr., Roig 1981, cap. IV; Mahr 2000, p. 111.

58 Cfr., Roig 1974, p. 228; Mahr 2000, pp. 72-77.

59 Cfr., Mahr 2000, pp. 117-121.

60 Cfr., Mahr 2000, p. 118.

61 Cfr. Santos Herceg 2010, p. 56.

62 Cfr., Roig 1981, cap. IV; 1994, p. 10.

63 Cfr., Mahr 2000, pp. 164-170, 193-201. 
a la historia latinoamericana. Roig aboga para una valoración más positiva de la representación (Vorstellung) a la que Hegel relativiza por el concepto. La representación dejaría el espacio para rupturas, diferencias, argumenta Roig, respetando dimensiones no-reconciliadas. Sólo una dialéctica abierta de un discurso abierto es lo que correspondería a la realidad latinoamericana. ${ }^{64}$

En la concepción del sujeto que está integrado en un nosotros y en una historia, Günther Mahr identifica una respuesta a la crítica de Santiago Castro-Gómez $\left(1958\right.$ - ). ${ }^{65}$ Este autor colombiano discute la importancia que el sujeto tiene en la filosofía de Roig (y Zea). Sin embargo, el sujeto que comprende Roig no es más el sujeto aislado que conquista su mundo, sino que se trata de un sujeto determinado por la alteridad y su situación histórica; no es un sistema cerrado. Roig salva el sujeto igualmente contra la idea de Hegel según la cual la moralidad del sujeto tiene que integrase en una ética objetiva. Cada meta-narración ética tiene que nacer por la moralidad intersubjetiva. En el caso de Latinoamérica, esta moralidad del sujeto se opone muchas veces a la meta-narración ética oficial que sirve, de hecho, sólo a la opresión. Por ello Roig habla de una moral de la emergencia. ${ }^{66}$ Es el respeto por el otro, es su moralidad, que deja crecer la idea de la dignidad humana, que sirve a su vez de manera universal como idea regulativa. ${ }^{67}$ Entonces, Roig no sacrifica el sujeto a un sistema o principio abstracto, en cambio salva su moralidad y la narración del individuo. Por otra parte no favorece un subjetivismo moral, sino la conexión de los sujetos entre ellos, «el nosotros», como origen de la idea de la dignidad del hombre. Como idea regulativa, esta idea de la dignidad del hombre no forma un sistema integralista, más bien ofrece una orientación universal basada en la intersubjetividad de cada sujeto concreto y empírico. ${ }^{68}$ Roig no comparte el pensiero debole de Gianni Vattimo (1936 -), frente a ello lista unos ejemplos en que la referencia aun a la metafísica muestra su potencial emancipador y no represivo: como es el caso histórico donde los campesinos mexicanos usaban la virgen de Guadalupe como símbolo en la lucha contra el poder colonial. ${ }^{69}$ Además respeto a los derechos humanos, Roig prefiere un pensamiento fuerte. Dado que este fuerte pensamiento busca un entendimiento del sujeto empírico en su dignidad, Roig atribuye a su planteamiento una capacidad intercultural.

La orientación al sujeto empírico toma en serio todas las producciones del sujeto, es decir también su productividad cultural. Por eso Roig integra en su enfoque igualmente el pensamiento indígena que está en camino hacia una forma filosófica, en esta línea se refiere al trabajo importante de Miguel León Porti-

64 Cfr., Roig 1981, cap. V.

65 Cfr., Castro-Gómez 1996, pp. 113-120; Mahr 2000, pp. 164-170.

66 Cfr., Mahr 2000, pp. 171-191.

67 Cfr., Roig 1994, pp. 173-186.

68 Cfr., Mahr 2000, pp. 171-176.

69 Cfr. Roig 1993, p. 118; Mahr 2000, p. 204. 
lla (1926 -) de La filosofia náhuatl (1956). Roig sabe interpretar el mito de los Mayas según el cual los hombres son creados por los dioses de maíz como ilustración «de la autosuficiencia, del autohacerse por parte del hombre»: ${ }^{70} \mathrm{el}$ hombre se crea de lo que come y produce de una planta de cultivo. «El ser humano es creado creándose a sí mismo, creado desde su propio impulso creador.» ${ }^{71} \mathrm{La}$ interpretación y traducción filosóficas del mito revelan su potencial filosófico y lo abren al diálogo intercultural. Esta interpretación del mito ilustra como Roig niega el absoluto hegeliano y pone en su lugar al hombre como sujeto empírico y creador.

Hemos tocado sólo unas partes de la filosofía de Roig que se refieren a Hegel. No obstante de la crítica que desarrolla Roig, Hegel inspira a Roig a salvar conceptualmente el sujeto humano, a defender una obligación universal de la filosofía a partir de lo concreto y empírico y a la apertura del pensamiento para un diálogo intercultural.

\section{HENRIQUE DUSSEL: ANALÉCTICA}

En una medida mayor que Zea y Roig, Henrique Dussel (1934 - $)^{72}$ se refiere preferentemente a la filosofía de Hegel por contrastar la propia posición filosófica. A diferencia de Zea y Roig, Dussel no recibe o usa el pensamiento de Hegel como inspiración de su concepción filosófica. Su filosofía de la liberación e historia se orientan a los críticos de Hegel, en particular a la filosofía de la alteridad de Emmanuel Levinas (1905/6-1995). ${ }^{73}$ Junto con Zea y Roig (y Francisco Miró Quesada y Abelardo Villegas), Dussel firmó la Declaración de Morelia en agosto de $1975^{74}$ donde rechazaban «la dependencia de unos pueblos en exclusivo beneficio de otros». Según Dussel, el pensamiento de Hegel justifica la dependencia de los pueblos no-europeos ante los pueblos europeos. Por eso no puede - como la filosofía de la liberación proyectada - servir por hacer «expreso el derecho de todo pueblo a libertad como autodeterminación». Se debe favorecer una filosofía de la alteridad que ponga las bases para una filosofía de la liberación.

Por su simpatía hacia la filosofía de la alteridad, y a diferencia de Zea y Roig, Dussel no acepta la dialéctica hegeliana como modo de pensar. Del filóso-

70 Reyes 2008, p 180.

71 Roig 2004, http://www.ensayistas.org/critica/generales/C-H/roig.htm, 20 de marzo de 2014.

72 Cfr., Beorlegui 2006, pp. 730-755; Sauerwald 1985, pp. 233-237; Peter 1996, pp. 1351.

73 Cfr., Peter 1996, p. 20; Dussel 2009, pp. 359-368.

$74 \mathrm{Cfr}$., http://www.ensayistas.org/critica/manifiestos/morelia.htm. 
fo y teólogo argentino Juan Carlos Scannone, ${ }^{75}$ Dussel recibe el concepto de la analéctica, una combinación de las palabras analogía y dialéctica para interpretar la relación entre los sujetos humanos. ${ }^{76}$ La analogía permite ver en cada semejanza entre dos realidades una siempre mayor desemejanza entre ellas. Por eso, el otro del sujeto no pierde su desemejanza, su alteridad - su exterioridad como dice con Levinas - cuando el sujeto identifica aspectos comunes entre sí y el otro. Sin embargo, a diferencia de la analogía, la dialéctica subraya las dos realidades estando en una relación recíproca, de tal modo que una realidad no puede estar sin la otra, como sujeto y objeto. En este sentido Dussel pone de relieve que la persona humana no puede estar sin otras personas. Por evitar que esta necesidad dialéctica quite la libertad y alteridad en las relaciones, Dussel insiste en la desemejanza de la analogía. Afirmando la analogía, Dussel critica igualmente la idea de una equivocación completa entre sujeto y objeto, entre sujeto y sujeto, porque ella coincide con la imposibilitad de cada comprensión del otro. La concepción analéctica permite además presuponer una realidad absoluta, un Dios personal. A diferencia de Hegel, un Dios concebido de forma analéctica no amenaza la libertad humana. Dussel reconcilia la filosofía de la liberación con la tradición judía-cristiana- musulmana.

Mientras Dussel comparte la crítica de Hegel hecha por Theodor W. Adorno (1903-1969) que se expresa en el dicho «El todo es lo no verdadero», porque este todo de un sistema destruye al otro, alteridad y diferencia, ${ }^{77}$ el filósofo mexicano-argentino diseña una totalidad ética como responsabilidad universal, cuyo criterio para su autenticidad es el compromiso para las personas marginadas. En este sentido modifica la filosofía de Levinas que no cualifica al otro en términos sociales-económicos. Esta ética correspondería a la realidad de Latinoamérica y del mundo entero. El imperativo categórico dice de manera global, libera al pobre, al oprimido. Sólo una ética así permitiría reconstruir la visión universal de filosofía de Hegel. Contra la tradición europea cuyo punto culminante representa la filosofía idealista, Dussel redefine la actividad cognitiva del hombre: conocer no termina en la unidad entre sujeto y objeto, en la apropiación del objeto por el sujeto, sino consiste en un acto de re-conocimiento, en un acto ético que respeta la verdad del otro y asume responsabilidad para él.

Dussel critica la filosofía de la historia de Hegel porque pone a Europa en el centro. Por eso Dussel esboza historiografias de otros centros del mundo, de

75 Cfr., Scannone 2003, p. 163-175, acá punto 2.4.2. Sobre la influencia de Levinas en Scannone cfr., Beorlegui 2006, 706-710.

76 Cfr., Dussel 1977, p. 186: «El momento analéctico nos abre al ámbito metafísico (que no es el óntico de las ciencias tácticas ni el ontológico de la dialéctica negativa), refiriéndose semánticamente al otro. Su categoría propia es la de exterioridad; por ello, el punto de partida de su discurso metódico (método más que científico y dialéctico positivo), es la exterioridad del otro; su principio no es el de identidad sino el de separación, distinción.»

77 Adorno 2001, p. 48. 
Asia y de Latinoamérica. ${ }^{78}$ El llamado descubrimiento de América, lo interpreta como un encubrimiento de la identidad original ${ }^{79}$ interpretación esta que a propósito del V Centenario del descubrimiento de América, Zea afirma igualmente. ${ }^{80}$ En este contexto Dussel, junta como Roig, el ego-cartesiano - reproducido en Hegel - con el ego conquistador de los europeos y busca verificaciones para esta tesis en las biografías de Hernán Cortés y Moctezuma II (14651520). ${ }^{81}$ El Yo de Cortés, nacido como «hijo de alguien» alcanza a la subjetividad por la conquista. ${ }^{82}$ Con Friedrich Nietzsche (1844-1900), Dussel enuncia que en este yo europeo se manifiesta la «voluntad de dominio» que es la historia originaria del ego cogito. Mientras que Cortés reconoce en el ego de Moctezuma sólo otro yo que se puede someter y reducir a un momento de la conquista, Moctezuma reconoce en Cortés un ego divino, por consiguiente Cortés puede reconocer su ego como algo absoluto, legitimado a gobernar y dominar. Dussel se refiere a la mitología azteca para justificar esta tesis, donde las tradiciones hablaban del regreso de los dioses, de Quetzalcoatl y decían «del este vendrán hombres blancos y barbados»». ${ }^{83} \mathrm{La}$ aparición de los Españoles para Moctezuma correspondería a esta descripción; fue así que adornaron a Cortes con el traje simbólico de Quetzalcóatl y lo veneraron como divinidad. Según Dussel esta afirmación mitológica del ego conquistador verificó su opinión alta de sí, su superioridad imaginada. Esta experiencia de la superioridad divina del ego europeo funda la idea filosófica del yo como sujeto incondicionado y base de toda certitud y verdad. «El «yo conquisto» al indio americano será el antecedente práctico-político, un siglo antes, del «yo pienso» teórico-ontológico cartesiano. Por ello, la historia empírica de la conquista... es el origen mismo de la Modernidad en cuanto tal, de la experiencia ontológica desde donde se entiende la nueva filosofía europea. ${ }^{84}$ Este ego cartesiano manifiesta su divinidad en la idea hegeliana del espíritu absoluto que se realiza por el espíritu humano. Europa ocupa una posición divina y absoluta que no deja espacio para exterioridad. La filosofía política de Hegel, la teoría del estado absoluto, permite un dominio global, realiza políticamente el yo absoluto. ${ }^{85}$

Esta interpretación dusseliana del encuentro entre Cortés y Moctezuma provoca discusiones. Ya existen dudas respecto a la autenticidad de esta tradición que transmite el mito del regreso de los dioses en su aplicación a Cortes. ${ }^{86}$ Pero

78 Cfr., Dussel 1993, pp. 75-119.

79 Cfr., Dussel 1993, pp. 26-43.

80 Cfr., Zea 1985; Estermann 2008, pp. 106-109.

81 Cfr., Dussel 1993, pp. 135-141.

82 Cfr., Dussel 1993, pp. 45-55.

83 Carrillo de Albornoz 2004, pp. 210-245.

84 Dussel 2007, pp. 194-195.

85 Cfr., Dussel 2007, pp. 380-391.

86 Cfr., Prem 2008, pp. 256-258. 
prescindiendo de esta cuestión literaria e histórica, la presumida divinidad mitológica del ego de Cortés no está en una directa conexión con la filosofía del sujeto en Descartes y Hegel. El yo de Descartes resulta más de una debilidad de la situación europea que de una superioridad: resulta de la ruptura de la unidad cristiana, de la guerra de los 30 años y la necesidad de buscar un nuevo fundamento común de certeza en una época en que mundo y ordo exteriores y espirituales se deshacen - resulta también de una crises personal de Descartes. ${ }^{87} \mathrm{El}$ idealismo de Hegel no resulta tampoco de una fase de superioridad europea, sino de muchos cambios y crisis: revolución francesa, guerras napoleónicas, restauración. Sólo Napoleón que vendió Louisiana en 1803, encuentra siempre su veneración por Hegel. Por las tensiones y contradicciones que determinan el tiempo de Hegel, su filosofía ofrece estrategias de reconciliación. La emigración a las Américas no está marcada por un espíritu de una conquista orgullosa, sino muchas veces está motivada por opresión y pobreza. El idealismo nace en crisis de la ilustración y de la metafísica insuficiente frente a un empirismo fuerte. Por eso la Fenomenología parte de la certeza sensible para relativizarla y abrir una comprensión a las dimensiones transcendentales y espirituales de la percepción de la realidad. El joven Hegel prefiere ideas románticas que abren el horizonte del hombre al absoluto, no hay un Yo que conquista fácilmente la dimensión de la transcendencia. Hegel tiene que capacitar a la filosofía para tocar lo absoluto. También la idea problemática del estado absoluto hay que entender a partir del motivo de la reconciliación. La filosofía de Dussel no reconoce de manera convincente la situación concreta en que Descartes y Hegel diseñan sus conceptos idealistas. Aún Levinas, que Dussel elige como su filosofo por concebir el pensamiento latinoamericano, sabe interpretar a Descartes de forma distinta: Levinas quita la visión según la cual el pensamiento cartesiano implementaría un Yo absolutista: La idea innata de Dios no indica el ser absoluto del Yo (o a Dios en las manos del hombre), sino una pasividad a priori del sujeto; lo innato precede a cada actividad del sujeto, lo condiciona, por eso, ni siquiera sabe dominar autónomamente su propia identidad que depende de la existencia de Dios. ${ }^{88}$

Dussel tiene razón al pensar que el idealismo de Hegel no alcanza a abrir el sujeto permanentemente hacia la alteridad; la dialéctica cierra el sujeto en sí. Por ello el concepto de la analéctica representa una idea crítica e innovadora. Sin embargo, no convence el salto dialéctico del lado del sujeto al lado del otro porque de tal manera se reproduce la unilateralidad. Una dialéctica equilibrada ha de buscar la reconciliación de los extremos.

87 Cfr., Röd 1982, pp. 17-33.

88 Cfr., Levinas 1981, pp. 98-99 


\section{IGANACIO ELLACURÍA: RESPECTIVIDAD}

Ignacio Ellacuría (1930-1989), jesuita español, filósofo y teólogo en San Salvador, naturalizado salvadoreño, asesinado por militares salvadoreños, ${ }^{89}$ define como objeto de la filosofía la historia, cuyo fin es la liberación y la libertad de la persona humana ${ }^{90}$ Respecto a la unidad del objeto filosófico, Ellacuría comparte la tesis de Hegel y Karl Marx (1818-1883) en la que se afirma que la totalidad de la realidad, la historia, es una y única tanto en la dimensión sincrónica como en la diacrónica. La filosofía hace parte de esta unidad. Del filósofo español Xavier Zubiri (1898 - 1983), Ellacuría recibe el termino técnico de «respectividad» que intenta expresar la «unidad primaria» que precede a cada relación entre realidades. Lo que es real es «intrínseca y constitutivamente respectiva a cualquier otra cosa real». ${ }^{91}$ La unidad de la cosas no se reduce a un solo concepto, no se constituye por un espíritu absoluto. Son las cosas mismas que existen y se desarrollan respectivamente. Ellacuría une el planteamiento hegeliano y marxista entendiendo la unidad como un proceso de lo material y lo espiritual porque lo material es la condición de lo espiritual, lo espiritual presupone lo material. En el proceso del desarrollo las dos dimensionen se presuponen recíprocamente. Una reflexión epistemológica sostiene esta síntesis de lo material y espiritual. Según Ellacuría la sensibilidad pertenece al intelecto, el intelecto no existe sin sensibilidad, se trata siempre de una inteligencia sentien$t e .^{92}$ En contraste, Hegel presenta una inteligencia que trasciende a la sensibilidad y se concibe como lógica. Contra esta tendencia que Ellacuría designa logificación y que a su juicio excluye muchas formas de la precepción de la realidad, posiciona, junto con Zubiri, el concepto de la inteligencia sentiente. A la logificación de la inteligencia corresponde la entificación de la realidad, es decir, la reducción de la realidad al ser que, según la tradición occidental y sobretodo idealista, es la realidad reducida a la relación con intelecto. La realidad es más amplia como el intelecto es más amplio que la lógica.

La definición del objeto de la filosofía para Ellacuría excluye a un Dios transcendente, por otro lado la realidad está abierta a la transcendencia - el desarrollo de la realidad hacia realidades cualitativamente nuevas muestra esta apertura como característica general.

Ellacuría descubre una estructura dialéctica en el desarrollo; ella funciona como motor e implica el principio de la negación determinada: lo superior en el

89 Cfr., Beorlegui 2006, pp. 779-791; Fornet-Ponse 2008; Fornet Ponse 2013, pp. 181303.

90 Cfr., Ellacuría 1990, p. 39; 2010, pp. 15-43; 2005, pp. 63-92, 85: «La realidad histórica es el objeto último de la filosofía, entendida como metafísica intramundana, no sólo por su carácter englobante y totalizador, sino en cuanto manifestación suprema de la realidad.».

91 Ellacuría 2005, pp. 76-77.

92 Cfr., Ellacuría 2001a, pp. 297-317. 
desarrollo niega lo anterior resumiéndolo, sin anularlo. El último estadio del desarrollo dialéctico consiste en la aparición del «reino social de la libertad», ${ }^{93}$ que es momento en que el desarrollo se hace historia. Esta historia asume todo lo anterior, en consecuencia Ellacuría interpreta el desarrollo precedente de la naturaleza y de la vida como pre-histórico; en el desarrollo físico y biológico se muestra un momento de la historia: lo contingente, la casualidad, interacciones sorprendentes. ${ }^{94}$ Por ello Ellacuría relativiza el principio dialéctico del desarro1lo, en el sentido que la dialéctica no asume una forma unívoca, ni formalista, ni mecánica. ${ }^{95}$ En la sociedad unos fenómenos se explicarían así por la dialéctica de las clases, como la interdependencia de riqueza y pobreza, ${ }^{96}$ otros no. La dialéctica presupone una fuerza positiva que supera un estado deficiente - una fuerza como el bien común que niega el mal común No existe en la dialéctica un automatismo que cambie una injusticia social en justicia; son los esfuerzos de hombres que pueden cambiar la historia de explotación y darle una dirección nueva. Se observa la dialéctica de amo y esclavo en la crítica que Ellacuría hace al gobierno salvadoreño, censurándolo por su servilismo ante el capital $;{ }^{97}$ según este autor «el Estado dijo: «A sus órdenes mi capital».»" ${ }^{98}$ En el poder político, el amo, se hace esclavo, porque no se arma de valor contra el capital teniendo miedo de perder el poder, así, el poderoso no ejerce el poder y por eso se convierte en esclavo. Sólo el gobierno que se arriesga a perder el poder tiene la libertad de ejercerlo a favor de la justicia.

Ellacuría insiste en la concretización e historización de ideas abstractas como el bien común o de los derechos humanos. De tal modo, toma en serio el principio hegeliano de la mediación, pero en una dirección opuesta. Como Roig, Ellacuría, está convencido que sólo por lo concreto y regional se alcanza lo universal sin concebir una universalidad que tienda a la violencia. Por su experiencia sabe que los derechos pueden ser máscara de injusticia social y de violencia. Por lo tanto, es indispensable desarrollar los derechos humanos a partir de situaciones concretas y determinadas. ${ }^{99}$

Por el motivo que Ellacuría interpreta el desarrollo de la realidad como historia e historia como el posible y esperado progreso de la conciencia de la libertad, implementa su filosofía de la liberación en una visión metafísica-ontológica. Mientras que Roig contrapone historia y ontología y critica la ontología como

93 Ellacuría 2005, p. 86.

94 Ellacuría 2005, pp. 86-88.

95 Ellacuría 2005, pp. 80-83.

96 Cfr., Ellacuría 1999, p. 300: «La pobreza que da cornadas es la que surge de su contraposición dialéctica con la riqueza, la que es el resultado de una civilización del capital, pero no la que resulta de una civilización del trabajo.»

97 Cfr., Ribera 2013, pp. 44-45.

98 Ellacuría 2005, pp. 649, 652-654.

99 Cfr., Ellacuría 2001b, pp. 207-225; 433-445, acá 436, 443. 
pensamiento estático, Ellacuría integra el ser en el drama de la libertad. De tal modo que el tema de liberación no queda como algo exterior frente a la realidad natural o algo puramente social, sino como aquello que ocupa el corazón del ser. En tanto que el fin de la evolución consiste en la libertad, se trata de una finalidad abierta, que se destaca de la finalidad del concepto hegeliano que realiza finalmente la identidad de sujeto y objeto sin dejar un espacio para alteridad y distancias. Además está claro, que Ellacuría interpreta la evolución natural desde la libertad del hombre, no ofrece una explicación al nivel de la ciencia natural que no dispone de la categoría de la finalidad como una categoría de sentido y de valor; sentido y valor no son objetos de las ciencias naturales, sino de las humanidades (Geisteswissenschaften, ciencias del espíritu). La lucha social y política por la liberación corresponde a la dinámica de la realidad entera, fuerzas contrarias de opresión no sólo se oponen al mundo humano sino al mundo entero. El planteamiento de Ellacuría de una filosofía de la liberación presenta por eso una visión más total. Lo que Alberdi pronunció un tema de la filosofía latinoamericana ganó en Ellacuría el centro de la realidad, el ser. Ellacuría disfruta de la filosofía de Hegel para implementar esta concepción global de la realidad.

\section{CONCLUSIÓN: UNIDAD COMO RESPONSABILIDAD E INTERCULTURALIDAD}

Estos pocos ejemplos de la influencia del pensamiento de Hegel en la filosofía latinoamericana (más allá del Krausismo) muestran su presencia «dialéctica»: Hegel está presente aún en filósofos que se oponen a sus conceptos. En la posmodernidad, se lanza la crítica de las meta-narraciones que determinarían la filosofía latinoamericana en su búsqueda de la identidad propia y del continente. Sociólogos revelan el carácter híbrido de muchas magnitudes sociales de las cuales se esperaba una contribución a la identidad, p. e. del elemento indíge$\mathrm{na},{ }^{100}$ en la medida que la filosofía posmoderna no enuncia la incompatibilidad de las culturas y de sus narraciones, sino permite o promueve un diálogo entre ellas, la posmodernidad abre el horizonte para una filosofía intercultural que tendría que partir de cada cultura buscando transversales ${ }^{101}$ de comunicación y comprensión entre culturas. Esta filosofía intercultural opta por una comprensibilidad recíproca de las culturas, ${ }^{102}$ comprensibilidad esta que encuentra su posibilidad en el hecho que las culturas mismas representan una realidad compleja y plural. Por eso la cultura propia facilita una compresión de la cultura distinta. La filosofía de Hegel puede ser interpretada como filosofía de la comprensión y responsabilidad universal. Como afirman Zea, Roig, Dussel y Ellacuría contra Hegel, no se manifiesta un espíritu absoluto en la historia como parte del mundo; es el espíritu del hombre que hace historia - y cultura. En términos hegelia-

100 Cfr., García Canclini 2008: Culturas híbridas.

101 Cfr., Wolfgang Welsch 2008.

102 Cfr., Fornet-Betancourt 1997; Estermann 1999, pp. 36-51; 2010. 
nos es el espíritu objetivo (aunque Hegel atribuye la cultura/arte, religión y la filosofía al espíritu absoluto) que resulta del diálogo intercultural y es (o subsiste como) la comprensión realizada. En otras palabras, es la dimensión antropológica de la que hablan Zea y Roig, es la dimensión de la libertad de que hablan Dussel y Ellacuría - y de la ontología en el sentido de Ellacuría que se manifiestan en las culturas y abren horizontes de comprensión. Roig y Ellacuría muestran también la necesidad de que principios universales como los derechos humanos tienen que pasar por la situación concreta para ganar su autenticidad -los derechos humanos pueden ser usados para construir una fachada bonita que sólo oculta injusticia. La filosofía latinoamericana establece, entonces, un criterio universal y concreto, es decir, un criterio antropológico para garantizar la verdadera universalidad de una afirmación: son los marginados, oprimidos, pobres. ${ }^{103} \mathrm{Si}$ un principio universal no respeta, ni cambia la situación de ellos, entonces, este principio favorece, aún sin querer, el poder que acepta y consolida la marginación. La filosofía de Hegel reinterpretada en términos latinoamericanos tiende a una unidad y a un espíritu de responsabilidad hacia los marginados. Podemos concluir: La historia es el progreso de la conciencia de la libertad si ella es igualmente el progreso de conciencia de la responsabilidad y del compromiso social.

Lo absoluto de Hegel puede ser interpretado como la última instancia ante la que se justifica la propia responsabilidad. Según la tradición judía es la instancia divina que reclama la justicia para las viudas y huérfanos, para los pobres y extranjeros. Este Dios no absorbe la alteridad-marginalidad, sino asume responsabilidad y solidaridad a favor de ella. Este Dios es el de la liberación e historia de la salvación. Según la tradición cristiana, Dios no es una unidad monolítica en oposición a la pluralidad de lo contingente, sino una unidad de relaciones trinitarias (Padre, Hijo y Espíritu). Hegel reconoce la idea (Vorstellung) de la Trinidad como clave para entender la unidad dialéctica de unidad y diferencia/alteridad. Lamentablemente Hegel no salva esta idea al nivel del concepto filosófico, sino que transforma la Trinidad en un sujeto absoluto que se realiza triádicamente. Por su concepto del absoluto, el filósofo alemán, margina la alteridad, resultando como consecuencia la exclusión que de lo absoluto hegeliano hacen representantes de la filosofía latinoamericana en su recepción de intuiciones inspiradas en Hegel mismo. La filosofía latinoamericana podría ser entendida como invitación a concebir un monoteísmo relacional y trinitario. La filosofía de la religión de Hegel ofrece el material para esta propuesta que, entre otros, el filósofo y teólogo argentino Juan Carlos Scannone, asume. ${ }^{104}$

103 Cfr., Scannone 2001: La irrupción del pobre y la pregunta filosófica en América Latina, pp. 61-74.

104 Cfr., Scannone 2005.

Suplemento 19 (2014) de Contrastes. Revista internacional de filosofía 


\section{REFERENCIAS BIBLIOGRÁFICAS}

ADORNO, T. W., 2001: Minima moralia. Madrid: Taurus.

ALBERDI, J.B., 2003: Ideas para presidir a la confección del curso de filosofia contemporánea, Argentina: El Cid Editor.

BEORLEGUI, C., 2006: Historia del pensamiento filosófico latinoamericano. Una búsqueda incesante de la identidad. $2^{\mathrm{a}}$ ed. Bilbao: Universidad de Deusto. CARRILLO-MOCTEZUMA, 2004: El semidiós destronado, Madrid: Espasa. CASTRO-GÓMEZ, S., 1996: Crítica de la razón latinoamericana, Barcelona: Puvill Libros.

DUSSEL-QUESADA-ROIG-VILLEGAS-ZEA, 2014: «Declaración de Morelia: Filosofía e Independencia», con motivo del Primer Coloquio Nacional de Filosofía, celebrado en la ciudad de Morelia, Michoacán (México), del 4 al 9 de agosto de 1975. Ed. digital de Marisa Muñoz. http://www.ensayistas.org/critica/manifiestos/morelia.htm.

DUSSEL, E., 1977: Filosofia de la liberación, México: Edicol.

- 2007: Política de la liberación. Historia mundial y crítica, Madrid: Trotta.

- 2009: Ética de la liberación en la edad de la globalización y de la exclusión. Madrid: Trotta.

ELLACURÍA I. 1990: Filosofía de la realidad histórica, San Salvador: UCA.

- 1999: «El desafío de las mayorías populares», en Escritos universitarios. San Salvador: UCA, pp. 297-306.

- 2001a: «La nueva obra de Zubiri: Inteligencia sentiente», en Escritos filosóficos, vol. III. San Salvador: UCA, pp. 297-317.

- 2001b: «Historización del bien común y de los derechos humanos en una sociedad dividida» e «Historización de los derechos humanos desde los pueblos oprimidos y las mayorías populares», en Escritos filosóficos, vol. III. San Salvador: UCA, pp. 207-225, 433-445.

- 2005: «A sus órdenes mi capital», en Escritos políticos, vol. I. San Salvador: UCA, pp. 652-654.

- 2010: Philosophie der geschichtlichen Realität. Aachen: Verlag Mainz.

ESTERMANN, J., 1990: Andine Philosophie. Eine kulturelle Studie zur autochthonen andinen Weisheit, Frankfurt am Main: IKO (Filosofía Andina: Estudio Intercultural de la Sabiduría Autóctona. Quito: Abya-Yala, 1998.)

- 2008: Leopoldo Zea interkulturell gelesen. Nordhausen: Traugott Bautz.

- 2010: Interculturalidad. Vivir la diversidad, La Paz: ISEAT.

FORNET-BETANCOURT, R., 1997: Lateinamerikanische Philosophie zwischen Inkulturation und Interkulturalität, Frankfurt am Main: IKO.

FORNET-PONSE, TH., 2013: Freiheit und Befreiung. Untersuchungen zur Kontextualität und Universalität des Philosophierens, Aachen: Verlag Mainz.

- 2008: Ignacio Ellacuría interkulturell gelesen. Nordhausen: Traugott. 
GARCÍA CANCLINI, N., 2008: Culturas hibridas. Estrategias para entrar y salir de la modernidad, Buenos Aires: Paidós.

HEGEL, G.W.F., 1986: Grundlinien der Philosophie des Rechts. Werke in zwanzig Bänden, ed. E. Moldenhauer y K.M. Michel, vol. 7. Frankfurt am Main: Suhrkamp.

- 1986: Phänomenologie des Geistes. Werke in zwanzig Bänden, ed. E. Moldenhauer y K.M. Michel, vol. 3. Frankfurt am Main: Suhrkamp..

- 1986: Vorlesungen über die Geschichte der Philosophie I. Werke in zwanzig Bänden, ed. E. Moldenhauer y K.M. Michel, vol. 18. Frankfurt am Main: Suhrkamp.

- 1986: Vorlesungen über die Philosophie der Geschichte. Werke in zwanzig Bänden, ed. E. Moldenhauer y K.M. Michel, vol. 12. Frankfurt am Main: Suhrkamp, 1986.

HOFSTÄTTER, L.O., 2006: Kontextuelle Philosophie. Die lateinamerikanische Geschichtsphilosophie des Leopoldo Zea als Ausgangspunkt und Grundlage einer lateinamerikanischen Philosophie., Aachen: Verlang Mainz.

LEVINAS, E., 1981: «Gott und die Philosophie», en CASPER, B., (ed.), Gott nennen. Phänomenologische Zugänge. Freiburg/München: Karl Alber, pp. 81123.

MAHR, G., 2000: Die Philosophie als Magd der Emanzipation. Eine Einführung in das Denken von Arturo Andrés Roig, Aachen: Verlag Mainz.

MARTÍ, J., 2005: «Nuestra América», en MARTÍ, J., Nuestra América, ed. Ministerio de Cultura. Caracas: Fundación Biblioteca Ayacucho, pp. 31-39.

PREM, H.J., 2008: Geschichte Alt-Amerikas, München: R. Oldenbourg Verlag. REYES, L. A., 2008: El pensamiento indígena en América. Los antiguos andinos, mayas y nahuas, Buenos Aires: Editorial Biblos.

RIBERA, R., 2013: «Ignacio Ellacuría y la dialéctica», en Estudios Centroamericanos 68, pp. 35-53.

RÖD, W., 1982: Descartes. Die Genese des cartesianischen Rationalismus. München: Beck.

ROIG, A., 1971: «Acerca del comienzo de la filosofía americana», en Revista de la universidad de México, 25, 8, pp. 1-4.

- 1974: «Bases metodológicas para el tratamiento de las ideologías», en VVAA (eds.), Hacia una filosofía de la liberación latinoamericana, Buenos Aires: Bonum, pp. 217-243.

- 1981: Teoría y crítica del pensamiento latinoamericano, México: FCE. citado según la publicación electrónica de 20 de marzo de 2014: http://www.ensayistas.org/filosofos/argentina/roig/teoria/

- 1986: «La inversión de la filosofía de la historia en el pensamiento latinoamericano», en Revista de Filosofía y Teoría Política, 26-27, pp. 170174.

- 1993: Rostro y filosofia de América Latina., Mendoza: EDIUNC. 
- 1994: «La ,Dignidad Humana y la Moral de la Emergencia en América Latina», en FORNET-BETANCOURT (ed.), Konvergenz oder Divergenz? Eine Bilanz des Gesprächs zwischen Diskursethik und Befreiungsethik., Aachen: Augustinus Verlag, pp. 173-186.

- 2003: «La condición humana. Desde Demócrito hasta el Popol Vuh», en Lit. lingüist., 14, publicación en el internet: http://www.scielo.cl/scielo.php?script=sci_arttext\&pid=S071658112003001400017 del 20 de marzo de 2014.

SALAZAR BONDY, A. 2006: ¿Existe una filosofía en nuestra América?, México: Siglo XXI.

SANTOS HERCEG, J., 2010: «Huellas de Hegel en el pensamiento latinoamericano. Sobre la concepción de Filosofía», en Revista de Hispanismo Filosófico 15, pp. 43-61.

SAUERWALD, G., 1986: «Zur Rezeption und Überwindung Hegels in lateinamerikanischer Philosophie der Befreiung. Ein Beitrag zur Darstellung ihres Konflikts in der Auseinandersetzung mit europäischem Denken», en NICOLIN-PÖGGELER, Hegel-Studien, 20. Bonn: Bouvier, pp. 221-245.

SCANNONE, J.C., 2001: «La irrupción del pobre y la pregunta filosófica en América Latina», en SCANNONE-REMOLINA (eds.), Filosofar en situación de indigencia, Madrid: Comillas 2001, pp. 61-74.

- 2003: «Actualidad y futuro de la Filosofía de la Liberación», en Erasmus. Revista para el diálogo intercultural 5, pp. 163-175.

- 2005: Religión y nuevo pensamiento: hacia una filosofía de la religión para nuestro tiempo desde América Latina. Barcelona: Anthropos.

SCHUTTE, O.M., 1990: «The Master-Slave Dialectic in Latin America: The Social Criticism of Zea, Freire, and Roig», en The Owl of Minerva, 22, pp. 5-18. WELSCH, W., 2008: Unsere postmoderne Moderne, Berlin: Akademieverlag. ZEA, L., 1974: Dependencia y liberación en la cultura latinoamericana, México: Joaquín Mortiz.

- 1985: «América: ¿Descubrimiento o encubrimiento?», en Cuadernos Americanos 258, 1, pp. 93-104.

- 1976: El pensamiento latinoamericano, Barcelona/México: Editorial Ariel.

- 1978: Filosofia de la historia Americana. México: FCE.

- 1990: Descubrimiento e identidad latinoamericana, México: UNAM.

Michael Schulz, es catedrático de filosofía y teoría de las religiones en la Rheinische Friedrich-Wilhelms Universität (Bonn, Alemania)

Líneas de investigación:

Filosofía y teoría de las religiones, filosofía latinoamericano, Trinidad, Hegel. 


\section{Publicaciones recientes}

2013: «Hermeneutics of Identity: Latin American Philosophy's Search for Selfdependence», in: Philosophy Study 24, pp. 768-795.

2013: «Filosofía ambiental y ética ecológica en perspectiva europea y latinoamericana: ¿Cómo justificar el valor propio de la naturaleza?», en La sostenibilidad en Latinoamérica. Hacia un buen vivir desde una perspectiva interdisciplinaria, Editorial San Marcos: Lima, pp. 15-34.

2013: «La filosofía empieza en el estómago. Miguel de Unamuno y su pensamiento vital. Un ejemplo práctico», en La sostenibilidad en Latinoamérica. Hacia un buen vivir desde una perspectiva interdisciplinaria, Editorial San Marcos: Lima, pp. 97-112.

Dirección electrónica: michael.schulz@uni-bonn.de 